\section{Commentary: Establishing poetic devices in the crafting of a per-oral endoscopic myotomy masterpiece}

\author{
Evan T. Alicuben, MD, and Ryan M. Levy, MD
}

Surgical management of achalasia has undergone a recent transformation with the development and widespread implementation of the per-oral endoscopic myotomy (POEM) procedure. Its popularity reflects growing interest in a lessinvasive option by not only clinicians but also patients seeking intervention. There is much debate over indications for use of POEM, but through this nebulous cloud, one thing has prevailed as an undisputable concept: competent performance of POEM requires advanced endoscopic skills.

In their video atlas, Raja and colleagues ${ }^{1}$ have delivered an essential guide for thoracic surgeons adopting POEM into their practice. The precise, detailed step-by-step description reflects the considerable experience and expertise of the authors. Each aspect of the procedure is masterfully demonstrated, from the mucosotomy to creation of the submucosal tunnel, full-thickness myotomy, and finally application of clips to close the mucosal defect. Inclusion of thoughtful tips to maintain a straight submucosal tunnel, especially for the challenging sigmoid esophagus, reflects the extensive experience of their group. The authors took a unique approach to the orientation of their videos with not just endoscopic views being shown but also direct views of the operating surgeon and a separate angle for the assistant. The inclusion of these 3 synchronized perspectives provides a truly comprehensive look at the critical aspects of the operation, and the effort put into creation of such complex videos should be commended.

\footnotetext{
From the Department of Cardiothoracic Surgery, University of Pittsburgh Medical Center, Pittsburgh, Pa.

Diclosures: The authors reported no conflicts of interest.

The Journal policy requires editors and reviewers to disclose conflicts of interest and to decline handling or reviewing manuscripts for which they may have a conflict of interest. The editors and reviewers of this article have no conflicts of interest.

Received for publication June 7, 2021; revisions received June 7, 2021; accepted for publication June 18, 2021; available ahead of print Aug 8, 2021.

Address for reprints: Ryan M. Levy, MD, Department of Cardiothoracic Surgery, UPMC Passavant, University of Pittsburgh Medical Center, 9100 Babcock Boulevard, Pittsburgh, PA 15237 (E-mail: levyrm@upmc.edu).

JTCVS Techniques 2021;10:513-4

2666-2507

Copyright (C) 2021 The Authors. Published by Elsevier Inc. on behalf of The American Association for Thoracic Surgery. This is an open access article under the CC BY-NCND license (http://creativecommons.org/licenses/by-nc-nd/4.0/).

https://doi.org/10.1016/j.xjtc.2021.06.043
}

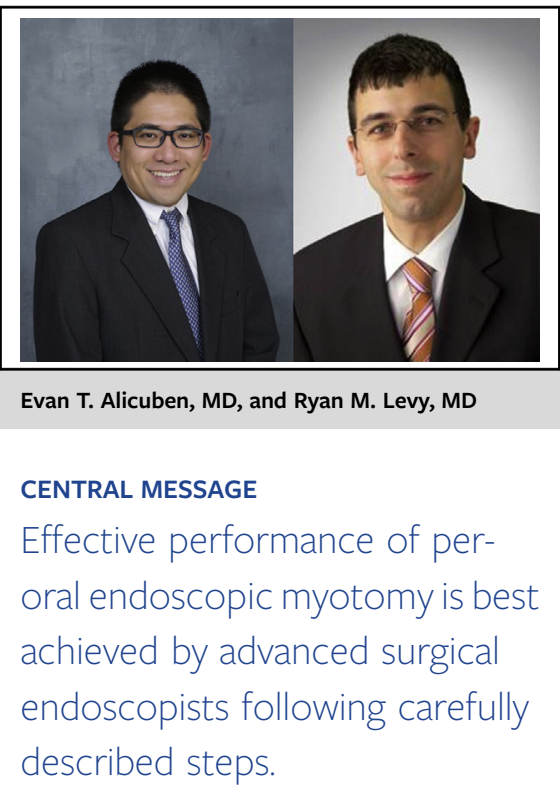

The authors acknowledge that their technique uses 2 providers, one managing the endoscope controls and tools while the other maintains scope and endoscope overtube stability. Working in concert allows for increased efficiency. However, the need for a second operator should not be viewed as a negative. Mastery of the techniques described still allows for the procedure to be performed by a single skilled endoscopist. In addition, using the 2-provider technique will facilitate training of less-experienced practitioners or surgical trainees.

Working to include POEM in a clinical practice remains challenging even for the skilled surgical endoscopist. For this reason, much speculation exists in the literature on the required learning curve to not just effectively but efficiently perform the procedure. ${ }^{2,3}$ Incorporation of the present guide in development of the POEM skillset may not just help progress through the learning curve but may also flatten it. Indeed, Raja and colleagues ${ }^{1}$ have provided thoracic surgeons with many poetic tips for successful creation of a POEM masterpiece. However, as they carefully point out, patient selection considerations are important. Laparoscopic Heller myotomy and Dor fundoplication may still be the preferred option in the management of some patients. As in much of thoracic surgery, dogmatic reliance on a single poetic paradigm is likely not the right answer.

\section{References}

1. Raja S, Adhikari S, Sanaka MR. Per-oral endoscopic myotomy for palliation of achalasia: a video atlas. J Thorac Cardiovasc Surg Tech. 2021;10:508-12. 
2. Kurian AA, Dunst CM, Sharata A, Bhayani NH, Reavis KM, Swanstrom LL. Peroral endoscopic esophageal myotomy: defining the learning curve. Gastrointest Endosc. 2013;77:719-25.
3. Liu Z, Zhang X, Zhang W, Zhang Y, Chen W, Qin W, et al. Comprehensive evaluation of the learning curve for peroral endoscopic myotomy. Clin Gastroenterol Hepatol. 2018;16:1420-6.e2. 